\title{
Amino acid concentrations in uterine fluid during early pregnancy differ in fertile and subfertile dairy cow strains
}

\author{
S. Meier, ${ }^{11}$ M. D. Mitchell, † C. G. Walker, ${ }^{\star}$ J. R. Roche,${ }^{\star}$ and G. A. Verkerk ${ }^{\star}$ \\ *DairyNZ Limited, Hamilton 3240, New Zealand \\ †Liggins Institute, The University of Auckland, Grafton 1145, New Zealand \\ ¥The University of Queensland, Centre for Clinical Research, Royal Brisbane \& Women's Hospital Campus, Herston, Queensland 4029, Australia
}

\begin{abstract}
The objective of this study was to determine if free AA concentrations in uterine luminal fluid (ULF) and plasma differed between dairy cow strains that differ phenotypically for fertility and to evaluate the effect of the presence of a conceptus on ULF AA concentrations. Uterine luminal fluid was obtained postmortem from cows characterized on the basis of genetic ancestry as fertile $(\mathrm{n}=11)$ or subfertile $(\mathrm{n}=11)$ strains. At slaughter, cows were at a similar stage of lactation (fertile, $85 \pm 1 \mathrm{~d}$ and subfertile, $87 \pm 1 \mathrm{~d}$ postpartum, respectively). Cows were slaughtered on either d 17 of the estrous cycle [nonpregnant $(\mathrm{n}=10)$ : fertile $\mathrm{n}=$ 5 ; subfertile $\mathrm{n}=5$ ] or $\mathrm{d} 17$ of pregnancy [ $10 \mathrm{~d}$ after embryo transfer, which was undertaken $7 \mathrm{~d}$ after estrus ( $\mathrm{n}=12$, pregnant): fertile $\mathrm{n}=6$, subfertile $\mathrm{n}=6$ ]. Uterine luminal fluid was collected from each uterine horn of the pregnant (gravid and nongravid horns) and nonpregnant (horn ipsilateral and contralateral to the corpus luteum) cows. Plasma harvested on the day of slaughter and ULF samples were analyzed for AA determination using HPLC. The main effects of genetic strain, reproductive status, and their interactions on ULF and plasma AA content were tested. Additionally, the effect of uterine horn on ULF AA was tested for the pregnant and nonpregnant cows. Reproductive status had the greatest effect on AA concentrations in ULF. The concentrations of Leu, Met, Phe, Val, 1-methyhistidine, Asp, essential, ketogenic, and branched-chain AA, and those AA classified as both glucogenic and ketogenic were greater in the ULF collected from pregnant cows, with taurine being lower. Additionally, we observed effects of uterine horn and genetic strain $x$ uterine horn interaction for ULF AA concentrations. Concentrations of the essential AA plus Met and Phe were greater in the ULF from the gravid horn, irrespective of strain. The ULF from the gravid horn of fertile cows contained the greatest concentrations of nones-
\end{abstract}

Received April 23, 2013.

Accepted November 8, 2013.

${ }^{1}$ Corresponding author: Susanne.Meier@dairynz.co.nz sential, glucogenic, branched-chain AA, and Leu, Thr, Ala, Ser, and Asp. With the exception of Asp, plasma AA profiles were not different in fertile and subfertile strains. These data support the hypothesis that reproductive status modifies the AA profiles of the ULF and that these profiles differ in fertile and subfertile genetic strains. Successful pregnancy depends on the complex interactions between the developing conceptus and uterine environment. Understanding the mechanisms contributing to maternal-conceptus communication using models with divergent fertility phenotypes could provide information regarding novel mechanisms to improve dairy cow fertility.

Key words: amino acid, uterine fluid, plasma, genetic strain

\section{INTRODUCTION}

Successful pasture-based dairying is dependent on a seasonal calving pattern so that peak pasture demand aligns with peak pasture availability (Holmes et al., 2002; Verkerk, 2003). Studies comparing North American (NA) and New Zealand (NZ) Holstein-Friesians (HF) report that, as a group, the NA HF strain has reduced pregnancy rates (Macdonald et al., 2008; Coleman et al., 2009) and conception rates (Horan et al., 2005) compared with the NZ strain in pasture-based systems. The underlying physiological differences that might explain differences in reproductive outcomes between NZ and NA HF strains remain poorly defined. Previous studies have reported differences between the NZ and NA strains, with lactating cows and postpubertal heifers from the NA (subfertile) strain reported to have longer luteal phase and estrous cycle compared with the NZ (fertile) strain (McNaughton, 2003; Meier et al., 2009b). Others have reported differences among these fertile and subfertile strains in either luteal or follicular characteristics (Horan et al., 2005), embryo quality (de Feu et al., 2008), and maternal environment (endometrial fatty acid content; Meier et al., 2009a). Additionally, genes implicated in immune tolerance to the embryo and luteolysis and genes that promote embryo growth and development were downregulated 
in the endometrium from NA HF cows compared with endometrial gene expression of NZ HF cows (Walker et al., 2012). Collectively, these data indicate that the uterine environment, early embryo growth, and signaling mechanisms between the preimplantation conceptus and the maternal environment contribute to differences in fertility of these genetic strains.

The survival of the embryo and the growth of the preimplantation conceptus, including its subsequent production of IFN- $\tau$ (Heap et al., 1979; Bazer et al., 1986; Robinson et al., 2006), are crucial in the successful establishment of pregnancy. The preimplantation conceptus receives its early nutrition from uterine secretions known as the histotroph (Roberts and Bazer, 1988). Amino acids are an important component of the histotroph, contributing to protein synthesis, acting as signaling molecules, and regulating embryo development and implantation (Steeves and Gardner, 1999; Van Winkle, 2001; Martin et al., 2003). Altering AA availability in culture modifies the subsequent production and use of AA by the embryo (Steeves and Gardner, 1999; Morris et al., 2002). Additionally, AA concentrations in the uterine luminal fluid (ULF) differ during the estrous cycle and with the presence of the preimplantation conceptus (Hugentobler et al., 2007; Groebner et al., 2011a). Groebner et al. (2011a) reported the effect of pregnancy on AA concentrations in the ULF at 12,15 , and $18 \mathrm{~d}$, with significant effects from d 15 of pregnancy onward. Together, these studies have identified the patterns of depletion and production of AA through the most critical stages for pregnancy recognition in cattle.

Aspects of embryo quality have been reported to differ between NZ and NA strains (Meier et al., 2009a); more recently, Walker et al. (2012) reported a downregulation of IFN- $\tau$ responsive genes, genes involved in preventing luteolysis and supporting embryo growth in the endometrium collected from NA cows. It was hypothesized that the reported effect of HF genetic strain (NZ and NA) on endometrial gene expression reported by Walker et al. (2012) is associated with differences in the composition of the ULF supporting the preimplantation conceptus. Therefore, the objectives of this study were (1) to determine if free AA concentrations in ULF differed among dairy cow strains, and (2) to evaluate the effect of pregnancy on ULF AA concentrations. Additionally, concentrations of plasma AA were evaluated.

\section{MATERIALS AND METHODS}

\section{Animals and Management}

Twenty-two of 27 Holstein-Friesian cows were used in this study (see Figure 1). Cows were in their second to fifth lactation and were from 2 genetic strains $[<23 \%$ NA genetics (fertile; $\mathrm{n}=11$ ) or $>92 \%$ NA genetics (subfertile; $\mathrm{n}=11$ )]. The 22 cows were in 2 reproductive states: $d 17$ of the estrous cycle, termed nonpregnant (fertile $\mathrm{n}=5$; subfertile $\mathrm{n}=5$ ) or having received an embryo by implant $10 \mathrm{~d}$ earlier, $7 \mathrm{~d}$ after estrus, termed pregnant (fertile $\mathrm{n}=6$; subfertile $\mathrm{n}=6$ ), from which a conceptus was retrieved in the uterine flushings after slaughter (see Figure 1). Cows were managed as a single herd, grazing fresh pasture in an intensive rotational manner as described previously (Roche et al., 2006). Cows were allocated a pasture allowance of $>40 \mathrm{~kg}$ of DM/cow per day (measured to ground level). Pasture grazing residuals were used to ensure adequate pasture allowance: postgrazing residuals of $>1,800 \mathrm{~kg}$ of $\mathrm{DM} /$ ha were targeted during spring. All procedures were undertaken with the approval of the Ruakura Animal Ethics Committee (Hamilton, New Zealand) in accordance with the New Zealand Animal Welfare Act (1999).

An average BW was calculated from daily BW measures taken over 4 consecutive days during the week before slaughter. An average BCS was calculated from individual scores of 6 body sites (on a scale of 1 to 10, 1 being emaciated, and 10 being obese; Roche et al., 2004). A composite milk sample obtained from the p.m. and a.m. milkings immediately before slaughter was analyzed for milk yield, fat, CP, and total solids (FT120, Foss Electric, Hillerød, Denmark). Table 1 provides a summary of the phenotypic descriptions of the dairy cows used, including ancestry, age, BW, BCS, DIM, milk yield, milk composition, and pedigree information at the time of slaughter.

\section{Reproductive Management}

All animals enrolled in the study were free of purulent vaginal discharge following the assessment of the vaginal contents (Metricheck device; Simcro Tech, Hamilton, New Zealand; McDougall et al., 2007) before the initiation of the estrous synchrony program, and had not been treated for mastitis during that lactation. Cows were grouped by calving date, and estrous cycles were synchronized at similar DIM (fertile: $60 \mathrm{~d}$; subfertile: $58 \mathrm{~d}$; nonpregnant: $58 \mathrm{~d}$, pregnant: $60 \mathrm{~d}$ : $\mathrm{SE}=4.6$ d) using a controlled intravaginal drug-release device containing progesterone (1.38 g; CIDR-B, Zoetis, Auckland, New Zealand) inserted for $8 \mathrm{~d}$ (day of insertion $=$ $\mathrm{d}-8)$. On the day of insertion, cows were injected with $2 \mathrm{~mL}$ of estradiol benzoate (2 mg i.m., Cidirol Bomac Laboratories Ltd., Auckland, New Zealand). All cows received an injection of sodium cloprostenol $(500 \mu \mathrm{g}$, EstroPlan, Parnell Laboratories NZ Ltd., Auckland, New Zealand) on the morning and afternoon of d 6 and 


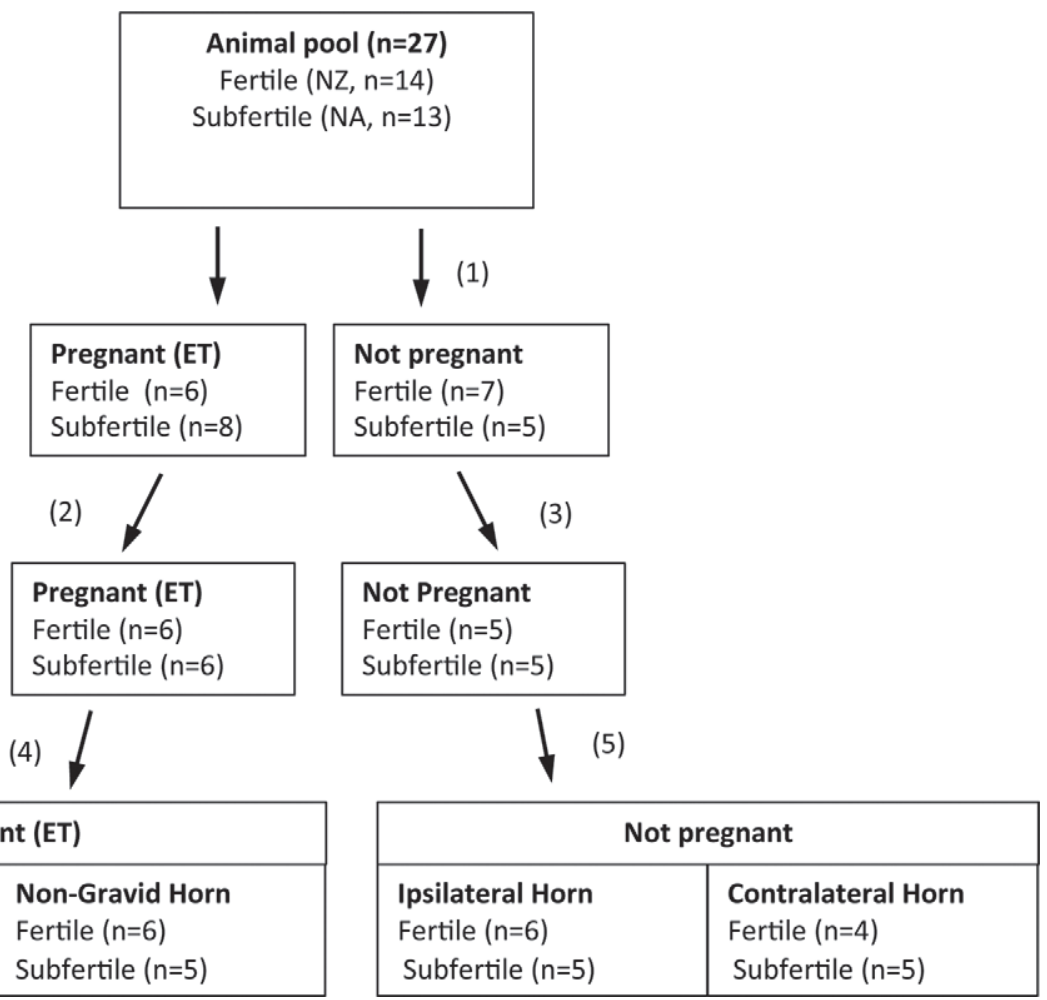

Figure 1. Overview of the experimental design for the uterine fluid AA analysis at d 17 of pregnancy (embryo transfer on d 7) and estrous cycle (not pregnant). (1) Excluded 1 cow as the ipsi- and contralateral horns could not be identified (no ovaries recovered at slaughter); (2) excluded 2 cows because pregnancy was not confirmed (no embryos recovered); (3) fertile $(\mathrm{n}=2)$ excluded for low progesterone $(<2 \mathrm{ng} / \mathrm{mL})$ on d 17; (4) trophoblast tissues were recovered from both horns in 1 cow, and (5) 1 cow had a corpus luteum on each ovary. NZ = New Zealand/ fertile, NA = North American/subfertile; ET = embryo transfer.

an injection of GnRH analog buserelin $(10 \mu \mathrm{g}$, Receptal, Intervet Schering-Plough Ltd., Upper Hutt, New Zealand) $24 \mathrm{~h}$ after CIDR device removal. Estrus was detected using tail-paint (Macmillan et al., 1988), with the day after $\mathrm{GnRH}$ injection designated as $\mathrm{d} 1$ of the estrous cycle.

Before estrous synchronization, cows were randomized to the pregnant or nonpregnant group. Cows allocated to the nonpregnant group received no further treatment. Those allocated to the pregnant group received a high-quality (Grade 1) expanded blastocyst (IETS, 2009) using nonsurgical embryo transfer into the uterine horn ipsilateral to the palpable corpus luteum (CL), $7 \mathrm{~d}$ following GnRH injection. Embryos were randomly allocated to be transferred into the NZ and NA cows assigned to the pregnant group. Embryos were generated in vitro from ovaries collected from a local commercial abattoir using a standardized technique (Thompson, 2000). Ovaries were collected from cows processed through the abattoir. The donor cows were mixed-age Holstein-Friesian or crossbred dairy cows in late gestation. Briefly, cumulus-oocyte complexes (COC) were aspirated from follicles 3 to
$8 \mathrm{~mm}$ in diameter, washed in HEPES-buffered tissue culture medium-199 supplemented with $10 \%$ fetal calf serum, and then cultured in $50-\mu \mathrm{L}$ drops $(10$ COC per drop) of maturation medium under mineral oil for 24 $\mathrm{h}$ at $39^{\circ} \mathrm{C}$ and $5 \% \mathrm{CO}_{2}$ in humidified air. The medium used for maturation was tissue culture medium-199, supplemented with $10 \%$ fetal calf serum, $10 \mu \mathrm{g} / \mathrm{mL}$ follicle-stimulating hormone, $10 \mu \mathrm{g} / \mathrm{mL} \mathrm{LH}$, and 1 $\mu \mathrm{g} / \mathrm{mL}$ estradiol- $17 \beta$. After 22 to $24 \mathrm{~h}$ of maturation, COC were washed twice in HEPES synthetic oviduct fluid (Thompson, 2000) and transferred to fertilization drops.

Oocytes were fertilized using semen from a single bull routinely used for in vitro fertilization (Karl Dustin, Friesian 92304, Livestock Improvement Corp., Hamilton, New Zealand). After separation on a Percoll discontinuous density gradient (45 to $90 \%$ ) spermatozoa were added to the fertilization drops (5 COC per $50-\mu \mathrm{L}$ drop under mineral oil) to give a final concentration of $1 \times 10^{6}$ sperm per $\mathrm{mL}$. After 20 to $24 \mathrm{~h}$ of fertilization, cumulus cells were removed and zygotes cultured in 20$\mu \mathrm{L}$ drops (10 zygotes per drop) of modified HEPES synthetic oviduct fluid under mineral oil. Embryo cul- 
Table 1. Phenotypic description of the dairy cows contributing to these data (group means and SE of these means), including genetic strain [\% North American (NA) ancestry], age, BW, BCS, and DIM at the time of slaughter, milk yield (kg/d) and composition, estimated breeding worth, and associated breeding values

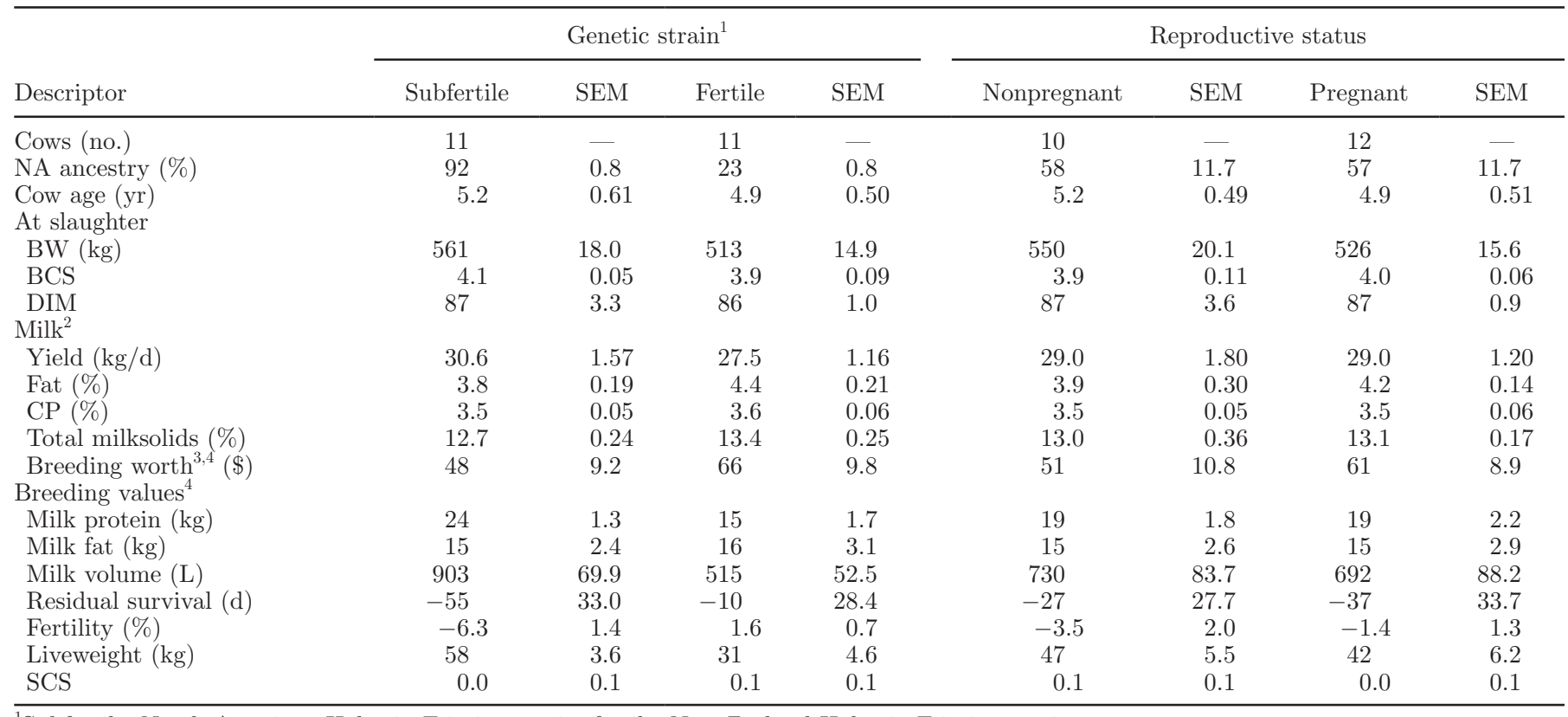

${ }^{1}$ Subfertile: North American Holstein-Friesian strain; fertile: New Zealand Holstein-Friesian strain.

${ }^{2}$ Milk yield and composition during the $24 \mathrm{~h}$ before slaughter.

${ }^{3}$ The sum of the breeding values information on the New Zealand Breeding Worth is available at the following website (http://www.nzael.co.nz/ all-about-bw).

${ }^{4}$ The reliabilities of the breeding worth and individual breeding values ranged between 40 and $60 \%$.

ture was performed in a modular incubation chamber in a humidified atmosphere of $5 \% \mathrm{CO}_{2}, 7 \% \mathrm{O}_{2}$, and $87 \% \mathrm{~N}_{2}$ for $7 \mathrm{~d}(\mathrm{~d} 0=\mathrm{d}$ of fertilization). On $\mathrm{d} 5$, the cleavage stage of the embryo was recorded before being transferred to fresh medium.

\section{Uterine Flushing and Blood Samples}

Uteruses were recovered and sampled postmortem within $60 \mathrm{~min}$ of slaughter (AgResearch Abattoir, Hamilton, New Zealand) on d 17 of the reproductive cycle $(\mathrm{n}=22)$. Each uterine horn was flushed with 20 $\mathrm{mL}$ of saline and the ULF recorded as being ipsilateral or contralateral to the ovary containing the CL or conceptus. Where pregnancy was confirmed by presence of a conceptus, the conceptus was removed before the ULF was processed. The cellular debris was removed via centrifugation; the sample was then lyophilized and reconstituted with distilled water containing protease inhibitors (Complete, Roche, Indianapolis, IN) before being dialyzed. The protein concentration was measured (Bradford, 1976) and samples stored at $-20^{\circ} \mathrm{C}$ until analyzed.

Blood was sampled on the day of slaughter (d 17); the sample was collected from the coccygeal vein into evacuated tubes (Becton Dickinson, Franklin Lakes,
NJ) containing sodium heparin anticoagulant. Blood was immediately placed in iced water and centrifuged within $1 \mathrm{~h}(12 \mathrm{~min}$ at $1,500 \times \mathrm{g})$. Aspirated plasma fractions were stored at -20 and $-80^{\circ} \mathrm{C}$ until analysis for AA concentrations.

\section{Amino Acids}

Sample Preparation. Plasma and ULF samples for measurement of AA were deproteinized by tungstate precipitation (Bloomfield et al., 2002). An aliquot of sample $(20 \mu \mathrm{L})$ was mixed with $160 \mu \mathrm{L}$ of $0.04 M_{2} \mathrm{H}_{2} \mathrm{SO}_{4}$ (including $15 \mu M$ norvaline as an internal standard) and left to stand on ice for 2 min before addition of $10 \%$ sodium tungstate $\left(\mathrm{Na}_{2} \mathrm{WO}_{4}, 20 \mu \mathrm{L}\right)$ and vortexing. The mixture was centrifuged at $4^{\circ} \mathrm{C}$ and $10,000 \times g$ for 10 min (Eppendorf 5417R, Hamburg, Germany) and the supernatant stored at $-80^{\circ} \mathrm{C}$ until assay.

$\boldsymbol{A} \boldsymbol{A}$ Analysis. Amino acid concentrations were measured by a fluorescent derivatization method utilizing the reaction of amino-nitrogen with 6-aminoquinolyl- $\mathrm{N}$ hydroxysuccinimidyl carbamate (Cohen and Michaud, 1993) and subsequent separation by HPLC.

Before chromatography, AA were derivatized using the Waters AccQ Tag method (AccQ Tag Ultra Derivatization Kit Care and Use Manual, Waters Corp., 
Milford, MA). In brief, $20 \mu \mathrm{L}$ of the supernatant was mixed with $60 \mu \mathrm{L}$ of borate buffer $(\mathrm{pH} 8.8)$ in a glass tube, after which $20 \mu \mathrm{L}$ of $10 \mathrm{mM}$ AccQ-fluor reagent (6-aminoquinolyl- $N$-hydroxysuccinimidyl carbamate) in acetonitrile was added and mixed immediately. The solution was transferred to an HPLC injection vial and incubated at $55^{\circ} \mathrm{C}$ for $10 \mathrm{~min}$, after which $10 \mu \mathrm{L}$ of sample was injected onto the HPLC column.

The HPLC system utilized a Waters 2690 Alliance separation module (Waters Corp.), a Phenomenex Luna 3- $\mu \mathrm{m}$ C18(2) 100A 250- $\times$ 4.6-mm column at $35^{\circ} \mathrm{C}$ (Phenomenex, Auckland, New Zealand), and a Waters 2475 fluorescence detector set at an excitation wavelength of $250 \mathrm{~nm}$, an emission wavelength of 395 $\mathrm{nm}$, and gain of 10 . The mobile phase consisted of a buffer ( $80 \mathrm{~m} M$ sodium acetate, $3 \mathrm{~m} M$ triethylamine, 2.7 $\mu M$ disodium calcium EDTA) at $\mathrm{pH} 6.4$ (obtained by addition of orthophosphoric acid) run with a complex gradient of acetonitrile from 2 to $20 \%$ over $115 \mathrm{~min}$.

Data were captured using Waters Empower chromatography data software (Waters Corp.) and AA concentrations calculated from standard curves generated for each AA. The standard curves plotted the ratios of the AA or valine peak areas against concentration for each AA. The coefficient of variation for ULF and plasma AA ranged from 2 to $15 \%$, and from 0.1 to $22 \%$, respectively.

\section{Statistical Analyses}

The AA analyses were completed on ULF recovered from both uterine horns of 22 cows [pregnant $(\mathrm{n}=12)$ : fertile $(\mathrm{n}=6)$ and subfertile $(\mathrm{n}=6)$; nonpregnant $(\mathrm{n}=10)$ : fertile $(\mathrm{n}=5)$ and subfertile $(\mathrm{n}=5)]$. The cows and samples within each group are summarized in Figure 1. The groups evaluating the effect of uterine horn are summarized below. For the pregnant cows, conceptus tissue was situated in both uterine horns of 1 subfertile cow, thus contributing data to the gravid horn group twice (gravid, fertile $\mathrm{n}=6$, subfertile $\mathrm{n}=$ 7; nongravid fertile $\mathrm{n}=6$, subfertile $\mathrm{n}=5$ ). For the nonpregnant cows, 1 cow in the fertile group had 2 $\mathrm{CL}$, thus contributing data to analyses of ipsilateral ULF twice (ipsilateral: fertile $\mathrm{n}=6$, subfertile $\mathrm{n}=5$; contralateral: fertile $\mathrm{n}=4$, subfertile $=5$ ).

Statistical analyses were undertaken using GenStat Release 11 statistical package (Payne et al., 2008). Data are presented as means \pm standard error of the difference (SED) unless otherwise stated. Statistical significance was assumed at $P \leq 0.05$. No $P$-value adjustments were made although multiple measures were. Amino acids were analyzed both individually and as AA groups as defined in Table 2 .
Amino acid concentrations in the ULF were corrected for total protein content and are presented as milligrams per gram of total protein. Differences in AA concentrations in plasma and ULF were analyzed using mixed models. The model included strain, reproductive status, and their interactions as fixed effects, and cow within strain as a random effect. Separate analyses were completed to investigate differences in AA from ULF from the separate uterine horns, within cow for the pregnant (nongravid vs. gravid horn) and nonpregnant cows (ipsi- and contralateral relative to the CL), using mixed models. These models included strain, uterine horn, and their interactions as fixed effects, and cow within strain as a random effect.

\section{RESULTS}

Concentrations of grouped AA (expressed as $\mathrm{mg} / \mathrm{g}$ of protein and $\mu \mathrm{mol} / \mathrm{L}$ ) in ULF for the 2 strains and reproductive states are summarized in Table 3. Although trends were similar, adjusting for total protein concentrations $(\mathrm{mg} / \mathrm{g}$ of protein) reduced the number of significant effects compared with uncorrected data $(\mu \mathrm{mol} / \mathrm{L})$. Thus, the subsequent results relating to AA concentrations in ULF are corrected for total protein content $(\mathrm{mg} / \mathrm{g}$ of protein) with plasma AA presented as micromoles per liter.

Overall, strain and reproductive status had few effects on ULF AA concentrations (Table 3, Figure 2). We observed no effect of genetic strain on the grouped (Table 3) and individual AA (Figure 2A). When the AA were compared among pregnant and nonpregnant cows, the ULF from pregnant cows contained greater concentrations of essential, branched-chain, and ketogenic AA, those AA grouped as either glucogeneic or ketogenic $(P<0.05$; Table 3$)$, and Leu, and lesser concentrations of Tau $(P<0.05)$ compared with ULF from nonpregnant cows (Table 3, Figure 2B). No genetic strain by reproductive status interaction was evident.

We found significant differences among uterine horns, with the essential AA present in greater concentrations in the ULF of the gravid horn (gravid 3.72, nongravid $2.73 \mathrm{mg} / \mathrm{g}$ of protein, SED $=0.441 ; P=0.04)$. The gravid horn also contained greater Met and Phe compared with the nongravid horn (Table 4), irrespective of genetic strain.

Interactions between uterine horn and strain were evident for both the grouped (Figure 3) and individual AA (Table 4). The ULF collected from the gravid horn of the fertile strain contained the greatest concentrations of the nonessential, glucogenic, and branchedchain groups (interactions $P \leq 0.05$; Figure 3 ). Individual AA also elevated in the gravid horn of fertile 
Table 2. Amino acid names, abbreviations, and group classifications

\begin{tabular}{|c|c|c|c|c|}
\hline Name & Abbreviation & $\begin{array}{l}\text { Essential/ } \\
\text { nonessential }^{1}\end{array}$ & Metabolic $^{2}$ & Other ${ }^{3}$ \\
\hline Arginine & Arg & Essential & Glucogenic & Nitrogen \\
\hline Histidine & His & Essential & Glucogenic & \\
\hline Isoleucine & Ile & Essential & Either & Branched chain \\
\hline Leucine & Leu & Essential & Ketogenic & Branched chain \\
\hline Lysine & Lys & Essential & Ketogenic & \\
\hline Methionine & Met & Essential & Glucogenic & \\
\hline Phenylalanine & Phe & Essential & Either & \\
\hline Threonine & Thr & Essential & Either & \\
\hline Valine & Val & Essential & Glucogenic & Branched chain \\
\hline Alanine & Ala & Nonessential & Glucogenic & \\
\hline Asparagine & Asn & Nonessential & Glucogenic & \\
\hline Glutamine & Gln & Nonessential & Glucogenic & \\
\hline Glycine & Gly & Nonessential & Glucogenic & \\
\hline Hydroxyproline & Hyp & Nonessential & & \\
\hline Proline & Pro & Nonessential & Glucogenic & \\
\hline Serine & Ser & Nonessential & Glucogenic & \\
\hline Taurine & Tau & Nonessential & & \\
\hline Tyrosine & Tyr & Nonessential & Either & \\
\hline 1-Methylhistidine & MeHis & Other & & \\
\hline Aspartic acid & Asp & Other & Glucogenic & \\
\hline Citrulline & Cit & Other & & Nitrogen \\
\hline Glutamic acid & Glu & Other & Glucogenic & Nitrogen \\
\hline Ornithine & Orn & Other & & Nitrogen \\
\hline
\end{tabular}

${ }^{1}$ Other = may be either group.

${ }^{2}$ Glucogenic $=\mathrm{AA}$ that can be converted into glucose; ketogenic $=\mathrm{AA}$ that are converted into ketone bodies; either = AA that can be converted to either glucose or ketone bodies.

${ }^{3}$ Nitrogen $=$ those AA that are part of the nitrogen cycle.

strain included Leu, Thr, Ala, Ser, Asp, and Glu ( $P$ $\leq 0.05)$.

Neither genetic strain nor uterine horn (ipsi- or contralateral to the CL) affected AA concentrations in the
ULF of the nonpregnant cows (Figures $4 \mathrm{~A}$ and $4 \mathrm{~B}$ ). Overall, the plasma concentrations of individual AA (Figure 5A and 5B) were similar for the fertile and subfertile strains and in the pregnant or nonpregnant cows.

Table 3. Amino acid group concentrations ${ }^{1}$ in uterine luminal fluid (ULF) from cows of varying genetic ancestry ${ }^{2}$ and reproductive status $^{3}$

\begin{tabular}{|c|c|c|c|c|c|c|c|c|}
\hline \multirow[b]{2}{*}{ AA group $^{1}$} & \multicolumn{2}{|c|}{ Strain $^{2}$} & \multicolumn{2}{|c|}{ Reproductive status ${ }^{3}$} & \multirow[b]{2}{*}{$\mathrm{SED}^{4}$} & \multicolumn{3}{|c|}{$P$-value } \\
\hline & Subfertile & Fertile & Nonpregnant & Pregnant & & Strain & Status & $\begin{array}{c}\text { Strain } \times \\
\text { Status }\end{array}$ \\
\hline Cows (no.) & 11 & 11 & 10 & 12 & - & - & - & - \\
\hline \multicolumn{9}{|l|}{ ULF (mg/g of protein) } \\
\hline Essential & 3.20 & 3.00 & 2.97 & 3.23 & 0.744 & 0.89 & 0.68 & 0.30 \\
\hline Nonessential & 2.59 & 3.08 & 3.12 & 2.55 & 0.707 & 0.39 & 0.46 & 0.45 \\
\hline Other & 2.97 & 2.55 & 3.04 & 2.49 & 0.527 & 0.55 & 0.34 & 0.35 \\
\hline Glucogenic & 3.94 & 4.50 & 4.37 & 4.07 & 1.050 & 0.49 & 0.83 & 0.33 \\
\hline Ketogenic & 2.28 & 1.98 & 2.12 & 2.13 & 0.486 & 0.64 & 0.94 & 0.32 \\
\hline Either & 0.51 & 0.58 & 0.47 & 0.61 & 0.153 & 0.56 & 0.34 & 0.39 \\
\hline Branched chain & 0.59 & 0.71 & 0.45 & 0.86 & 0.197 & 0.56 & 0.05 & 0.44 \\
\hline Nitrogen & 2.89 & 2.48 & 2.95 & 2.41 & 0.510 & 0.55 & 0.33 & 0.34 \\
\hline \multicolumn{9}{|l|}{$\mathrm{ULF}(\mu \mathrm{mol} / \mathrm{L})$} \\
\hline Essential & 15.1 & 15.0 & 13.1 & 17.0 & 1.53 & 0.96 & 0.02 & 0.74 \\
\hline Nonessential & 19.6 & 21.2 & 22.3 & 18.4 & 3.16 & 0.58 & 0.23 & 0.68 \\
\hline Other & 12.4 & 11.5 & 12.2 & 11.7 & 0.96 & 0.32 & 0.60 & 0.85 \\
\hline Glucogenic & 26.6 & 29.4 & 28.21 & 27.8 & 3.53 & 0.40 & 0.90 & 0.61 \\
\hline Ketogenic & 10.3 & 9.9 & 9.1 & 11.2 & 1.00 & 0.66 & 0.05 & 0.97 \\
\hline Either & 2.5 & 2.7 & 2.2 & 3.0 & 0.39 & 0.51 & 0.04 & 0.64 \\
\hline Branched chain & 3.6 & 4.1 & 2.5 & 5.1 & 0.74 & 0.50 & 0.002 & 0.65 \\
\hline Nitrogen & 11.9 & 10.8 & 11.7 & 10.9 & 0.96 & 0.27 & 0.46 & 0.94 \\
\hline
\end{tabular}

${ }^{1}$ Individual AA contributing to these groups are described in Table 2.

${ }^{2}$ Subfertile $=$ North American Holstein-Friesian cows; fertile $=$ New Zealand Holstein-Friesian cows.

${ }^{3}$ Nonpregnant $=\mathrm{d} 17$ of the estrous cycle, pregnant $=10 \mathrm{~d}$ after embryo transfer on $\mathrm{d} 7$.

${ }^{4}$ Standard error of the difference. 
A
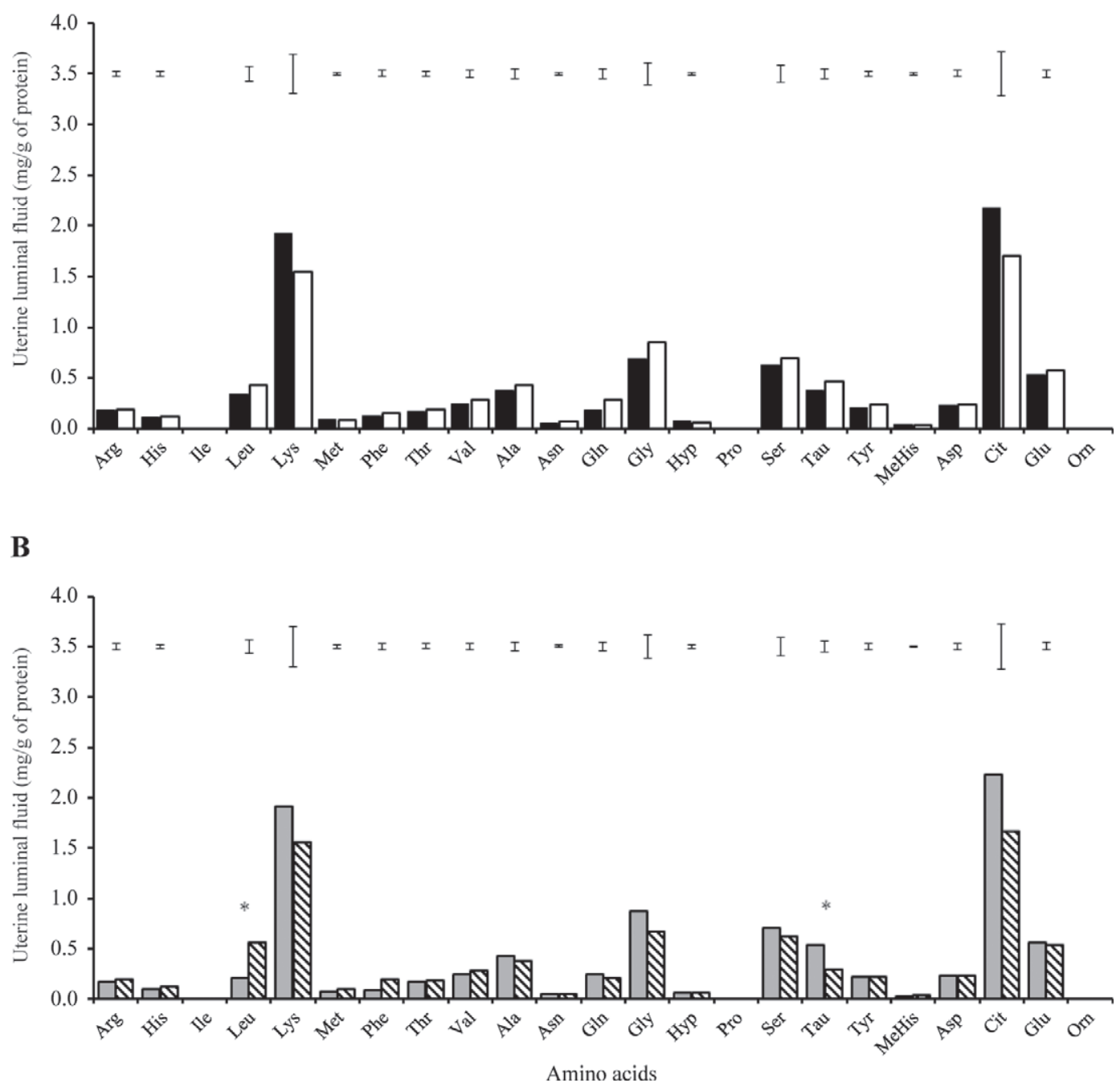

Figure 2. Amino acid concentrations $(\mathrm{mg} / \mathrm{g}$ of protein) in uterine luminal fluid from $(\mathrm{A})$ subfertile $(\mathrm{n}=11$; black $)$ and fertile $(\mathrm{n}=11$; white) dairy cow strains, and $(\mathrm{B})$ nonpregnant $(\mathrm{n}=10$; gray) and pregnant $(\mathrm{n}=12$; hatched) cows. Error bars represent the standard error of the differences for each $\mathrm{AA} .{ }^{*} P \leq 0.05$.

\section{DISCUSSION}

This study tested the hypothesis that cows originating from different HF genetic strains differ in the composition of AA within the ULF. Previous studies have characterized the HF population with NZ ancestry as having greater conception and pregnancy rates when evaluated within pasture-based farming systems (Horan et al., 2005; Macdonald et al., 2008; Coleman et al., 2009). Aspects of endometrial function from this study were reported by Walker et al. (2012). Endometrial gene expression differed in that upregulation of endometrial gene expression in the NZ strain was suggestive of a greater response to the presence of the preimplantation conceptus and more supportive of conceptus development. Within the constraints of the current study, which included only those cows in which a conceptus was recovered, differences in ULF AA composition in the gravid horn support the premise that the process of pregnancy recognition and early conceptus development differ among the HF strains. The lack of a difference in plasma and ULF AA among the nonpregnant group suggests that the null hypothesis is true in the nonpregnant group. The horn $\times$ strain interactions reported for the pregnant group may suggest that the differences reported were the result of a difference in the response to the presence of the conceptus by these strains, a premise that requires further investigation.

Independent of genetic strain, reproductive status modified AA concentrations in the ULF, in line with 
Table 4. The interaction between uterine horn and dairy cow strain ${ }^{1}$ on AA concentrations (mg/g of protein) in the uterine luminal fluid on d 17 of pregnancy ${ }^{2}$

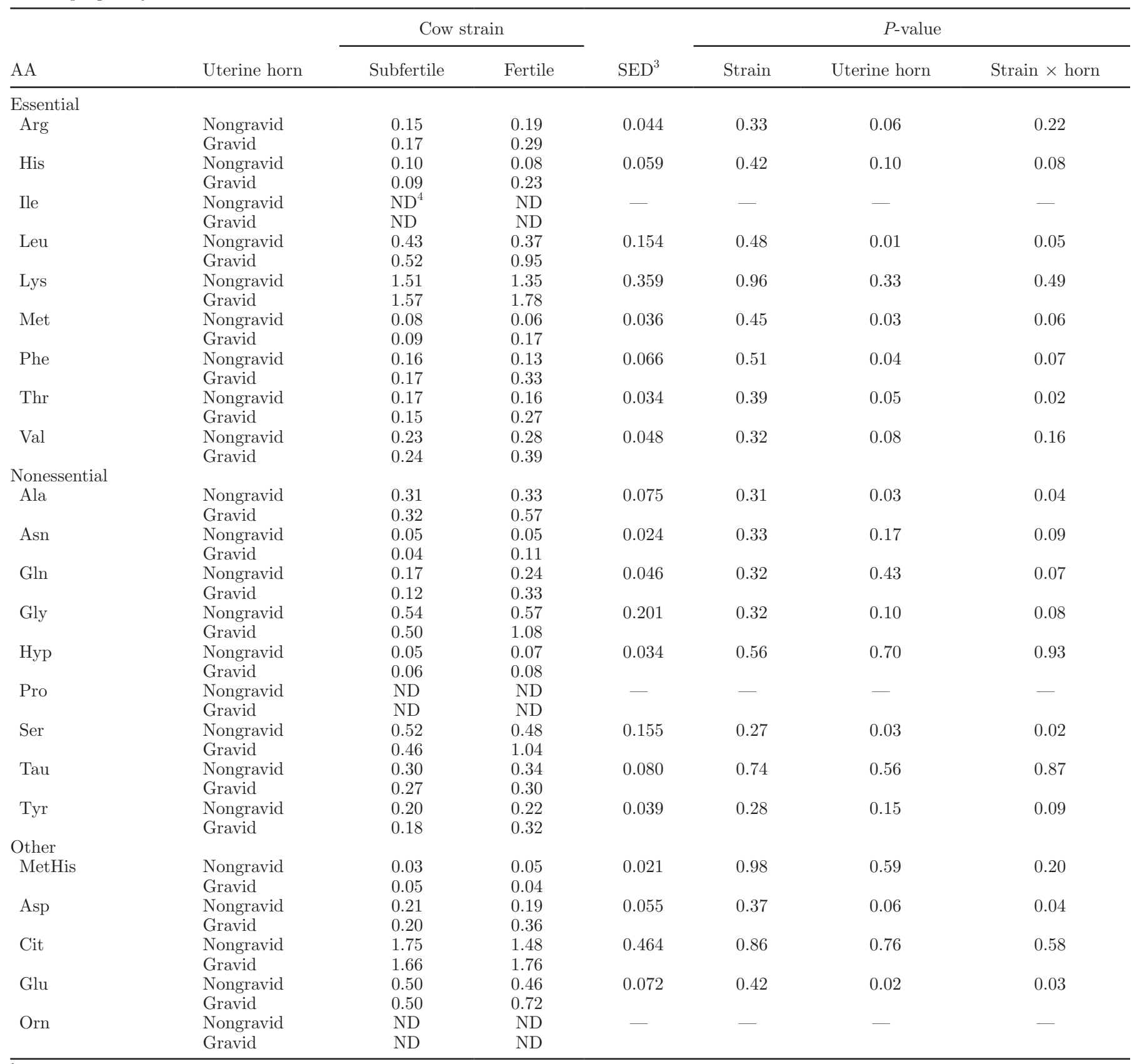

${ }^{1}$ Nongravid horn: subfertile $(\mathrm{n}=5)$, fertile $(\mathrm{n}=6)$; gravid horn: subfertile $(\mathrm{n}=7)$, fertile $(\mathrm{n}=6)$.

${ }^{2}$ Confirmed pregnant $10 \mathrm{~d}$ after embryo transfer on $\mathrm{d} 7$ of a synchronized estrous cycle.

${ }^{3} \mathrm{SED}=$ within-strain standard error of the difference.

${ }^{4} \mathrm{ND}=$ not detected.

previous reports (Morris et al., 2002; Groebner et al., 2011a). Amino acid profiles of the ULF from the gravid horns differed by HF strain, supporting the hypothesis that the composition of ULF is affected by genetic ancestry. The AA profiles were similar in the ULF of the nonpregnant groups, suggesting that the differences in
ULF AA observed in pregnant cows were the result of local changes within the reproductive tract in the presence of the preimplantation conceptus. Differences in the nutrient composition of ULF in the gravid horn from the fertile strain may reflect greater nutrient support for the preimplantation conceptus compared with 


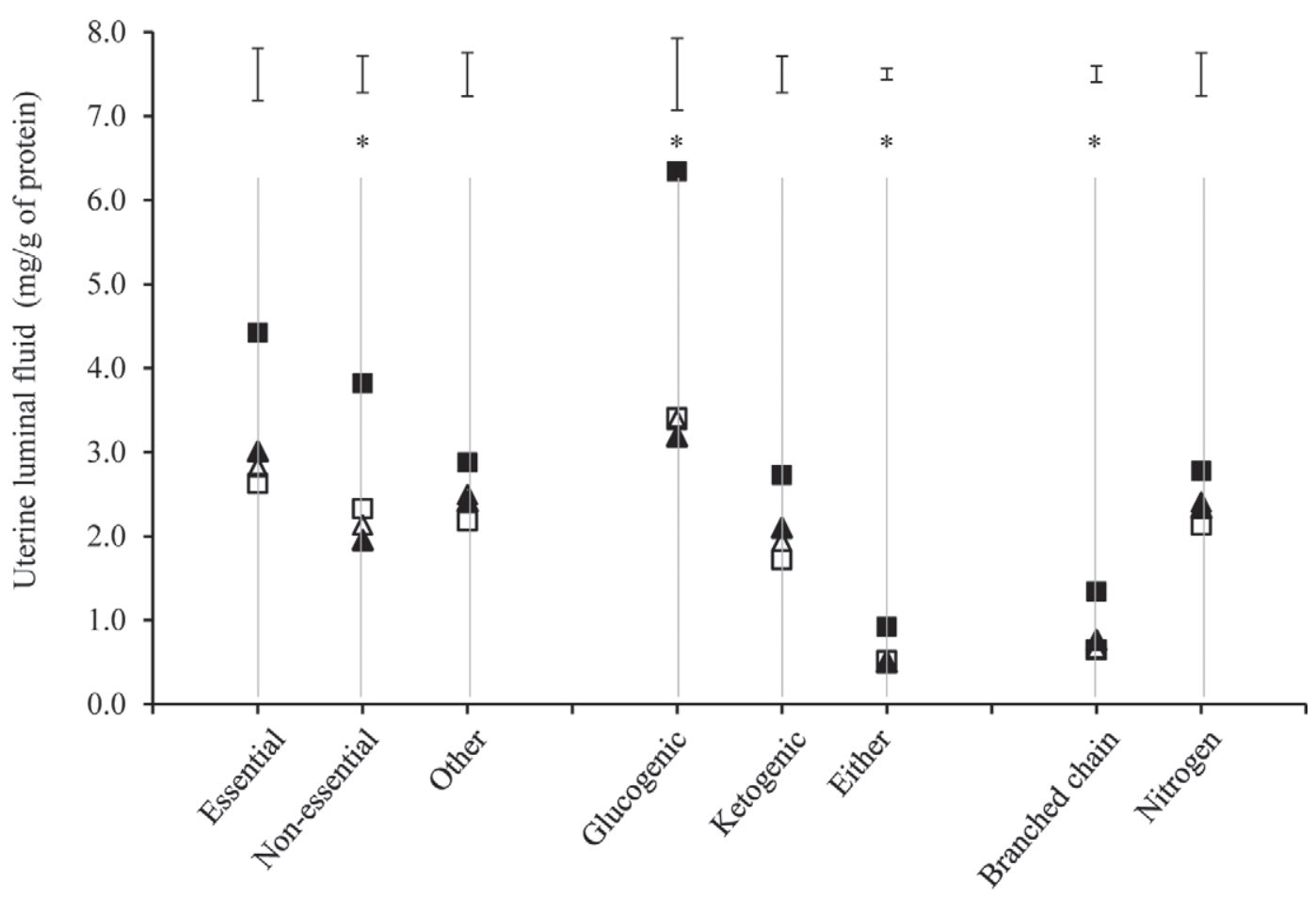

Amino acid groups

Figure 3. Concentrations of grouped AA ( $\mathrm{mg} / \mathrm{g}$ of protein) in uterine lumen fluid collected from Holstein-Friesian cows $10 \mathrm{~d}$ after embryo transfer [nongravid: subfertile $=\Delta(\mathrm{n}=5)$, fertile $=\square(\mathrm{n}=6)$; gravid: subfertile $=\boldsymbol{\Delta}(\mathrm{n}=7)$, fertile $=\mathbf{\square}(\mathrm{n}=6)$ ]. Error bars represent the standard error of the difference within strain. Amino acid groups as defined in Table $2 .{ }^{*} P \leq 0.05$ represent significant strain $\times$ uterine horn interactions.

the subfertile strain. Given that the conceptus originated from transferred embryos (i.e., of equivalent status), this also supports the premise that changes in the ULF AA in the gravid horn are associated with local changes and suggests that genetic strain can influence these. However, these pregnancies resulted from the transfer of embryos; thus, the effects of strain on AA concentrations may not be reflective of an individual cow's ability to establish an in vivo pregnancy.

In this study, concentrations of individual and grouped AA differed in the ULF of the gravid horns from the 2 genetic strains (with strain $\times$ horn interactions) during the preimplantation period. The ULF from the gravid horn of the fertile strain contained $50 \%$ more Arg, Glu, and Leu. The greater concentrations of Arg, combined with greater abundance of endometrial arginase I (Walker et al., 2012), provides evidence that mechanisms supportive of the preimplantation conceptus were upregulated in cows from the fertile HF strain. This suggests that the ULF of the fertile strain may support the production of nitric oxide and polyamines, compounds important for blastocyst growth and development and proliferation of the trophectoderm (Van Winkle, 2001; Martin et al., 2003).
Aspects of embryo quality from this study have been reported by Meier et al. (2009a). The conceptuses recovered from the NA HF strain were more variable in size (3.6-fold greater variation in length) than those from the NZ HF strain. As both the net appearance and disappearance of AA in culture medium depend on both the origin and quality of the embryo (Sturmey et al., 2010; Groebner et al., 2011b), the reported differences in AA profiles may represent differences in the quality or developmental stage of the conceptus present. The use of embryo transfer to generate the pregnant group was to ensure that a greater proportion of cows in this group were indeed pregnant. The transfer of only Grade 1 expanded blastocysts was to minimize variation in embryo quality associated with the in vitro process. Previous studies support a contribution by the preimplantation conceptus to the AA in the ULF (Morris et al., 2002; Groebner et al., 2011a). The period $15 \mathrm{~d}$ postconception was identified as a key period in which the conceptus modified AA profiles in the ULF. Individual embryos can significantly modify the availability of essential AA within the ULF; for example, defective embryos (produced through somatic cell nuclear transfer) were less able to induce endometrial AA transport, 
A

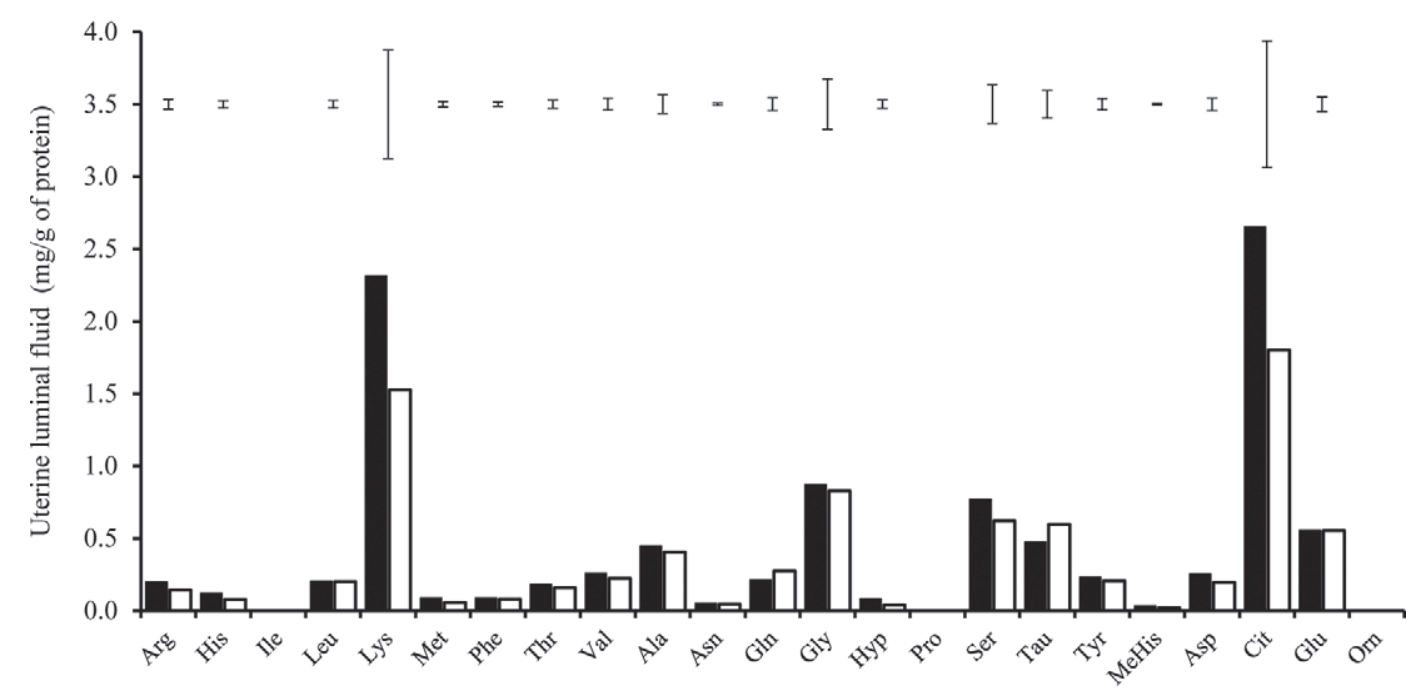

B

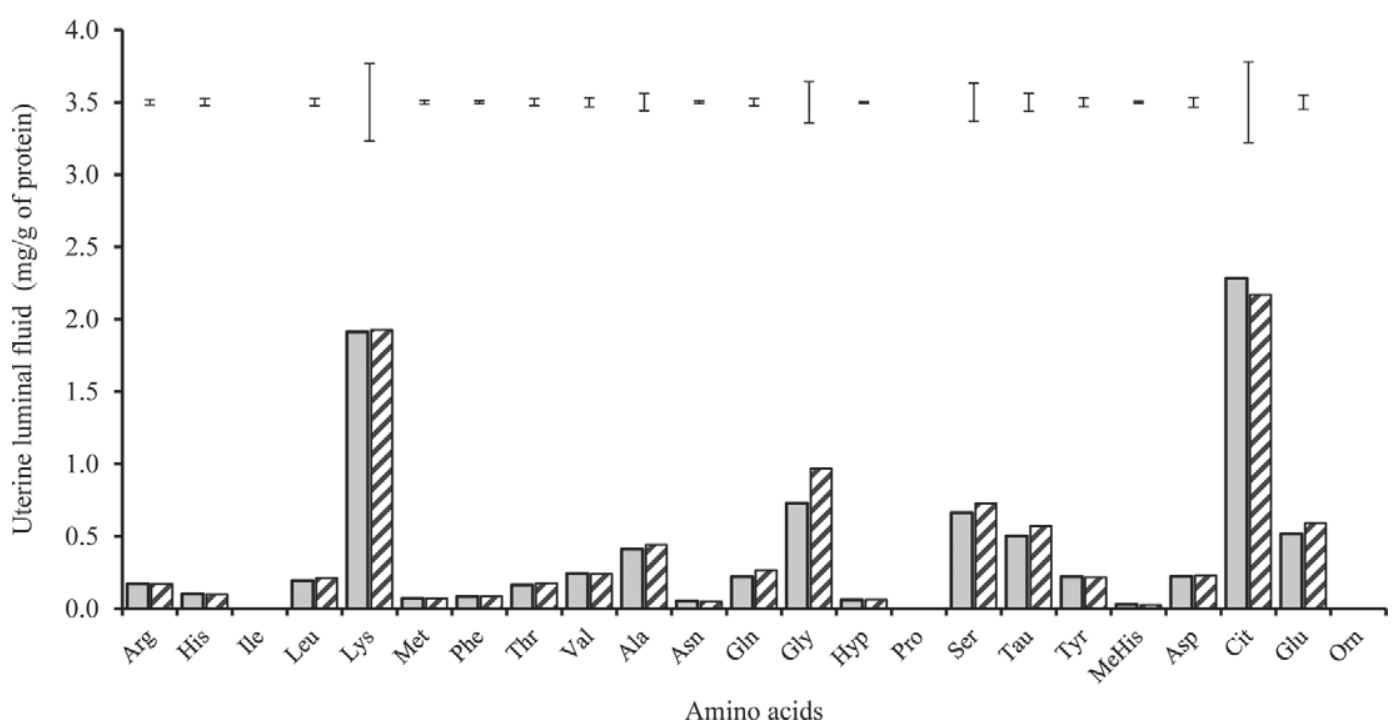

Figure 4. Concentrations of AA (mg/g of protein) in uterine luminal fluid on d 17 of the estrous cycle of nonpregnant cows comparing (A) subfertile (black, $\mathrm{n}=10$ ) and fertile (white, $\mathrm{n}=10$ ) dairy cow strains, and (B) the contralateral (gray, $\mathrm{n}=9)$ and ipsilateral (hatched, $\mathrm{n}=11$ ) horn to the corpus luteum. Error bars represent the standard error of the differences.

with the ULF having lower concentrations of AA compared with the ULF containing those embryos produced using traditional in vitro techniques (Groebner et al., 2011b). The reduction in ULF AA in the gravid horn of the subfertile strain may therefore reflect suboptimal regulation of ULF AA by the conceptus. Although a contribution by the oocyte to the observed differences cannot be excluded, the experimental approach in which only Grade 1 in vitro-derived embryos were transplanted may be expected to control much of this variation by the exclusion of lesser quality embryos. Results may differ if the conceptuses had been derived in vivo but this approach would have introduced further confounding factors. Taken together, these results support the hypothesis that the effect of $\mathrm{HF}$ genetic strain (NZ and NA) on endometrial gene expression reported by Walker et al. (2012) is associated with differences, localized to the gravid horn, in the composition of the ULF supporting the preimplantation conceptus.

Differences observed in the ULF AA profiles associated with pregnancy status (Table 1, Figure 1B), including the effect on branched chain AA, are consistent with previous reports for pregnant heifers (Groebner et al., 2011a) and ewes (Gao et al., 2009). Essential 


\section{A}

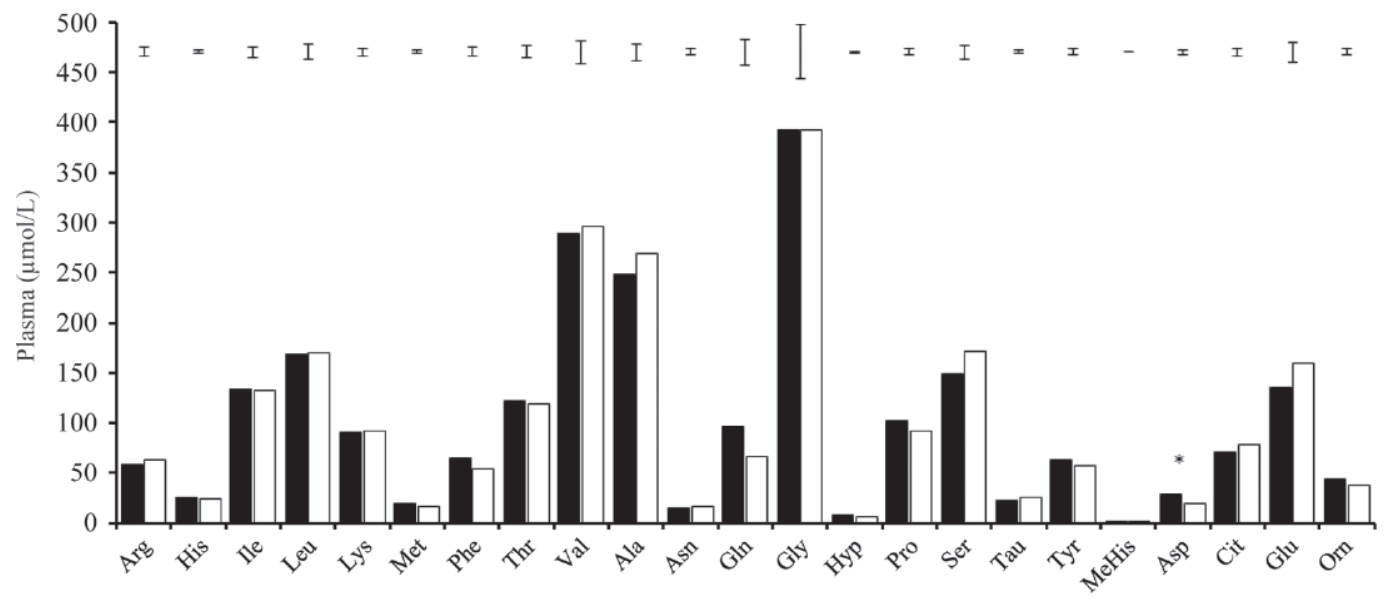

B

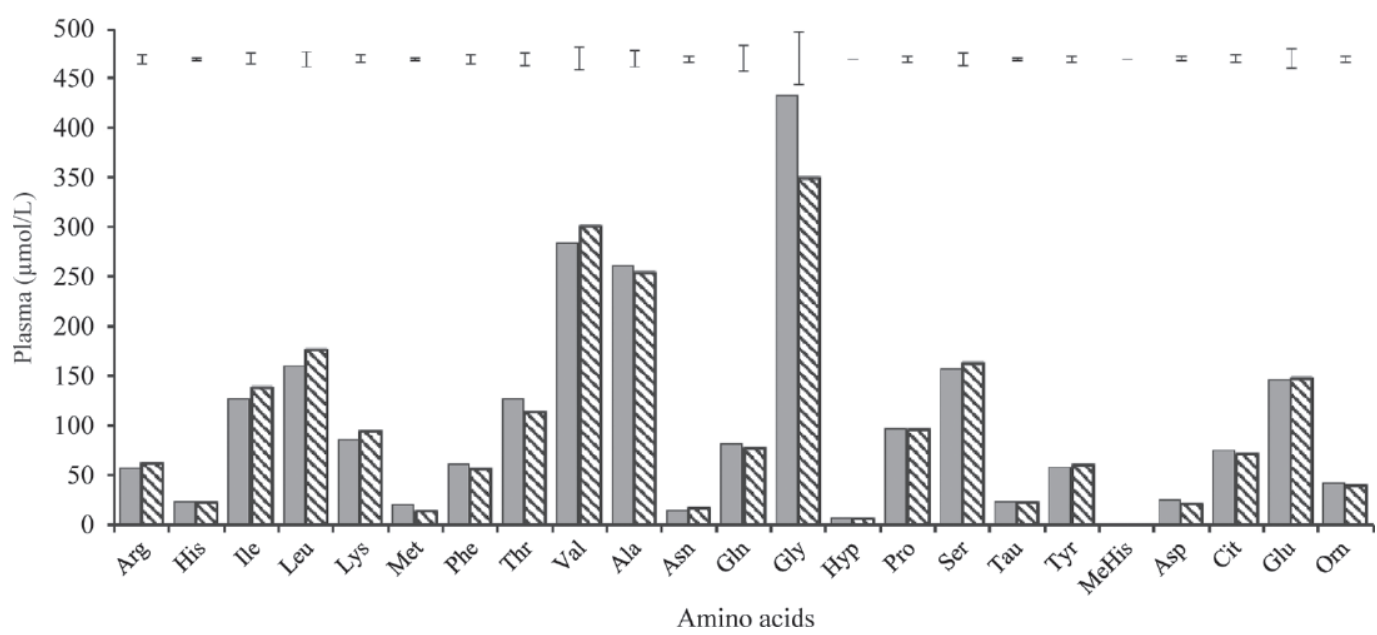

Figure 5. Plasma concentrations $(\mu \mathrm{mol} / \mathrm{L})$ of individual AA in $(\mathrm{A})$ subfertile (black, $\mathrm{n}=11$ ) and fertile $($ white, $\mathrm{n}=11)$ dairy cow strains, and $(\mathrm{B})$ cows that were nonpregnant (gray, $\mathrm{n}=10$ ) or pregnant following embryo transfer (hatched, $\mathrm{n}=12$ ). Error bars represent the standard error of the differences. ${ }^{*} P \leq 0.05$.

AA, including the branched-chain AA, are not synthesized by the preimplantation conceptus, but must be derived from the ULF. An increase in these nutrients $14 \mathrm{~d}$ after insemination would align with the increased requirements associated with the rapid growth of the conceptus (Betteridge et al., 1980; Grealy et al., 1996). Interestingly, Tau concentrations were lower in the ULF of pregnant cows. As Tau is important for supporting embryo growth and survival (Liu and Foote, 1995; Guérin et al., 2001), this reduction in Tau associated with pregnancy is, therefore, expected. Additionally, Tau concentrations in the ULF from cows with IVF embryos were lower than in ULF from cows that had received cloned embryos (Groebner et al., 2011b), suggesting that Tau concentrations may reflect the health of the embryo. Sturmey et al. (2010) identified that the developmental rates of embryos were associated with the rate at which $\mathrm{AA}$ were turned over by the embryo. By understanding the nutrient interactions within the pregnant uterine horn, effective and targeted interventions that can manipulate levels of ULF AA to benefit preimplantation conceptus development, and survival may become possible. Whether ULF AA can be manipulated in lactating cows to improve the developmental capabilities of preimplantation conceptuses and improve subsequent reproductive outcomes remains to be evaluated.

\section{CONCLUSIONS}

This study identified differences in the uterine environment of HF strains divergent for fertility following 
embryo transfer. Differences in ULF AA concentrations were not evident at the equivalent stage of the reproductive cycle in nonpregnant cows. The reported uterine horn $\times$ strain interactions in the pregnant cows support the evidence of the differential expression of genes supporting nutrient supply to the preimplantation conceptus among NZ and NA cows. Combined, these data support the premise that genetic strain can influence the uterine environment during early pregnancy. Investigations focused on changes at a local level, within the gravid horn, may provide insights into the mechanisms that affect the recognition of pregnancy and subsequent embryo survival.

\section{ACKNOWLEDGMENTS}

The authors acknowledge the assistance of farm and technical staff at DairyNZ Ltd. (Hamilton, New Zealand) and AgResearch (Ruakura, Hamilton, New Zealand) during the animal preparation and tissue collection phases. Eric Thorstensen (Liggins Institute, The University of Auckland, New Zealand) completed amino acid analyses. The technical assistance of Peter Gore (DairyNZ Ltd.), Marty Berg, Lindsay McGowan, Anita Ledgard, and Michael Agnew (AgResearch), and the statistical advice of Barbara Dow (DairyNZ Ltd.) are acknowledged. New Zealand dairy farmers through DairyNZ Inc. (AN708, AN808) and the Ministry of Business, Innovation and Employment (DRCX0301, DRCX0202, UOAX0814) provided funding for this work.

\section{REFERENCES}

Bazer, F. W., J. L. Vallet, R. M. Roberts, D. C. Sharp, and W. W. Thatcher. 1986. Role of conceptus secretory products in establishment of pregnancy. J. Reprod. Fertil. 76:841-850.

Betteridge, K. J., M. D. Eaglesome, G. C. Randall, and D. Mitchell. 1980. Collection, description and transfer of embryos from cattle 10 to 16 days after oestrus. J. Reprod. Fertil. 59:205-216.

Bloomfield, F. H., P. L. van Zijl, M. K. Bauer, and J. E. Harding. 2002. Effects of intrauterine growth restriction and intraamniotic insulin-like growth factor-I treatment on blood and amniotic fluid concentrations and on fetal gut uptake of amino acids in late-gestation ovine fetuses. J. Pediatr. Gastroenterol. Nutr. 35:287-297.

Bradford, M. M. 1976. A rapid and sensitive method for the quantitation of microgram quantities of protein utilizing the principle of protein-dye binding. Anal. Biochem. 72:248-254.

Cohen, S. A., and D. P. Michaud. 1993. Synthesis of a fluorescent derivatizing reagent, 6-aminoquinolyl-N-hydroxysuccinimidyl carbamate, and its application for the analysis of hydrolysate amino acids via high-performance liquid chromatography. Anal. Biochem. 211:279-287.

Coleman, J., K. M. Pierce, D. P. Berry, A. Brennan, and B. Horan. 2009. The influence of genetic selection and feed system on the reproductive performance of spring-calving dairy cows within future pasture-based production systems. J. Dairy Sci. 92:5258-5269.

de Feu, M. A., J. Patton, A. C. Evans, P. Lonergan, and S. T. Butler. 2008. The effect of strain of Holstein-Friesian cow on size of ovarian structures, periovulatory circulating steroid concentrations, and embryo quality following superovulation. Theriogenology 70:1101-1110.

Gao, H., G. Wu, T. E. Spencer, G. A. Johnson, X. Li, and F. W. Bazer. 2009. Select nutrients in the ovine uterine lumen. I. Amino acids, glucose, and ions in uterine lumenal flushings of cyclic and pregnant ewes. Biol. Reprod. 80:86-93.

Grealy, M., M. G. Diskin, and J. M. Sreenan. 1996. Protein content of cattle oocytes and embryos from the two-cell to the elongated blastocyst stage at day 16. J. Reprod. Fertil. 107:229-233.

Groebner, A. E., I. Rubio-Aliaga, K. Schulke, H. D. Reichenbach, H. Daniel, E. Wolf, H. H. D. Meyer, and S. E. Ulbrich. 2011a. Increase of essential amino acids in the bovine uterine lumen during preimplantation development. Reproduction 141:685-695.

Groebner, A. E., V. Zakhartchenko, S. Bauersachs, I. Rubio-Aliaga, H. Daniel, M. Buttner, H. D. Reichenbach, H. H. Meyer, E. Wolf, and S. E. Ulbrich. 2011b. Reduced amino acids in the bovine uterine lumen of cloned versus in vitro fertilized pregnancies prior to implantation. Cell. Reprogram. 13:403-410.

Guérin, P., S. El Mouatassim, and Y. Menezo. 2001. Oxidative stress and protection against reactive oxygen species in the pre-implantation embryo and its surroundings. Hum. Reprod. Update $7: 175-189$.

Heap, R. B., A. P. Flint, and J. E. Gadsby. 1979. Role of embryonic signals in the establishment of pregnancy. Br. Med. Bull. $35: 129-135$

Holmes, C. W., I. M. Brookes, D. J. Garrick, D. D. S. MacKenzie, T. J. Parkinson, and G. F. Wilson. 2002. Milk production from pasture: Principles and practices. Massey University, Palmerston North, New Zealand.

Horan, B., J. F. Mee, P. O'Connor, M. Rath, and P. Dillon. 2005. The effect of strain of Holstein-Friesian cow and feeding system on postpartum ovarian function, animal production and conception rate to first service. Theriogenology 63:950-971.

Hugentobler, S. A., M. G. Diskin, H. J. Leese, P. G. Humpherson, T. Watson, J. M. Sreenan, and D. G. Morris. 2007. Amino acids in oviduct and uterine fluid and blood plasma during the estrous cycle in the bovine. Mol. Reprod. Dev. 74:445-454.

IETS (International Embryo Transfer Society). 2009. IETS Manual. 4th ed. IETS, Champaign, IL.

Liu, Z., and R. H. Foote. 1995. Development of bovine embryos in KSOM with added superoxide dismutase and taurine and with five and twenty percent $\mathrm{O}_{2}$. Biol. Reprod. 53:786-790.

Macdonald, K. A., G. A. Verkerk, B. S. Thorrold, J. E. Pryce, J. W. Penno, L. R. McNaughton, L. J. Burton, J. A. Lancaster, J. H. Williamson, and C. W. Holmes. 2008. A comparison of three strains of Holstein-Friesian grazed on pasture and managed under different feed allowances. J. Dairy Sci. 91:1693-1707.

Macmillan, K. L., V. K. Taufa, D. R. Barnes, A. M. Day, and R. Henry. 1988. Detecting estrus in synchronized heifers-using tailpaint and an aerosol raddle. Theriogenology 30:1099-1114.

Martin, P. M., A. E. Sutherland, and L. J. Van Winkle. 2003. Amino acid transport regulates blastocyst implantation. Biol. Reprod. 69:1101-1108.

McDougall, S., R. Macaulay, and C. Compton. 2007. Association between endometritis diagnosis using a novel intravaginal device and reproductive performance in dairy cattle. Anim. Reprod. Sci. 99:9-23.

McNaughton, L. R. 2003. A comparison of reproductive performance and physiology of three genotypes of Holstein-Friesian dairy cattle. $\mathrm{PhD}$ Thesis. Institute of Veterinary, Animal and Biomedical Sciences. Massey University, Palmerston North, New Zealand.

Meier, S., A. J. Peterson, M. D. Mitchell, M. Littlejohn, C. Walker, and J. R. Roche. 2009a. Genetic strain and reproductive status affect endometrial fatty acid concentration. J. Dairy Sci. 92:3723-3730.

Meier, S., J. R. Roche, E. S. Kolver, G. A. Verkerk, and R. C. Boston. 2009b. Comparing subpopulations of plasma progesterone using cluster analyses. J. Dairy Sci. 92:1460-1468.

Morris, D. G., P. G. Humpherson, H. J. Leese, and J. M. Sreenan. 2002. Amino acid turnover by elongating cattle blastocysts recovered on days 14-16 after insemination. Reproduction 124:667-673. 
New Zealand Animal Welfare Act. 1999. Part 6. Use of animals in research, testing and teaching. http://www.biosecurity.govt.nz/regs/ animal-welfare/pubs/animals-used-in-research.

Payne, R. W., S. A. Harding, D. A. Murray, D. M. Soutar, D. B Baird, A. I. Glaser, I. C. Channing, S. J. Welham, A. R. Gilmour, R. Thompson, and R. Webster. 2008. The Guide to GenStat Release 11, Part 2. VSN International, Hemel Hempstead, UK.

Roberts, R. M., and F. W. Bazer. 1988. The functions of uterine secretions. J. Reprod. Fertil. 82:875-892.

Robinson, R. S., M. D. Fray, D. C. Wathes, G. E. Lamming, and G. E. Mann. 2006. In vivo expression of interferon tau mRNA by the embryonic trophoblast and uterine concentrations of interferon tau protein during early pregnancy in the cow. Mol. Reprod. Dev. 73:470-474.

Roche, J. R., D. P. Berry, and E. S. Kolver. 2006. Holstein-Friesian strain and feed effects on milk production, body weight, and body condition score profiles in grazing dairy cows. J. Dairy Sci. 89:3532-3543.

Roche, J. R., P. G. Dillon, C. R. Stockdale, L. H. Baumgard, and M. J. VanBaale. 2004. Relationships among international body condition scoring systems. J. Dairy Sci. 87:3076-3079.
Steeves, T. E., and D. K. Gardner. 1999. Temporal and differential effects of amino acids on bovine embryo development in culture. Biol. Reprod. 61:731-740.

Sturmey, R. G., P. Bermejo-Alvarez, A. Gutierrez-Adan, D. Rizos, H. J. Leese, and P. Lonergan. 2010. Amino acid metabolism of bovine blastocysts: A biomarker of sex and viability. Mol. Reprod. Dev. $77: 285-296$

Thompson, J. G. 2000. In vitro culture and embryo metabolism of cattle and sheep embryos - A decade of achievement. Anim. Reprod. Sci. $60-61: 263-275$.

Van Winkle, L. J. 2001. Amino acid transport regulation and early embryo development. Biol. Reprod. 64:1-12.

Verkerk, G. 2003. Pasture-based dairying: Challenges and rewards for New Zealand producers. Theriogenology 59:553-561.

Walker, C. G., M. D. Littlejohn, M. D. Mitchell, J. R. Roche, and S. Meier. 2012. Endometrial gene expression during early pregnancy differs between fertile and sub-fertile dairy cow strains. Physiol. Genomics 44:47-58. 